\title{
Adolescent Psychosocial Risk Factors for Severe Intimate Partner Violence in Young Adulthood
}

\author{
Danielle Keenan-Miller and Constance Hammen \\ University of California, Los Angeles
}

\author{
Patricia Brennan \\ Emory University
}

\begin{abstract}
The authors examined prospective measures of psychosocial risk factors as predictors of severe intimate partner violence among a community sample of 610 young adults at risk for intergenerational transmission of depression. The hypothesized risk factors were youth history of depression by age 15 and maternal history of depression. Youth social functioning at age 15 was tested as a mediator of these associations. Results showed that youth history of depression by age 15 predicted victimization at age 20 . Severe violence perpetration was predicted by maternal depressive history among women but not men. Youth social functioning was a partial mediator of both associations. In sum, the findings suggest that psychosocial factors observed in adolescence may contribute to the risk of experiencing severe intimate partner violence during young adulthood.
\end{abstract}

Keywords: depression, adolescence, intimate partner violence

The transition to adulthood is a particularly important developmental period in which to examine intimate partner violence (IPV). Recent research shows alarming levels of IPV occurring in teenage and young adult relationships. Community-based samples have consistently found that $20 \%-47 \%$ of teenage and young adult couples have experienced at least one act of physical violence (Andrews, Foster, Capaldi, \& Hops, 2000; Capaldi \& Crosby, 1997; Ehrensaft, Moffitt, \& Caspi, 2004; Magdol et al., 1997), albeit mostly mild forms of violence. Given the high personal and societal cost of IPV (Gerber, Ganz, Lichter, Williams, \& McCloskey, 2005; Max, Rice, Finkelstein, Bardwell, \& Leadbetter, 2004), clarification of risk factors that may aid in early detection and prevention is of paramount importance (Kim \& Capaldi, 2004; Lewis \& Fremouw, 2001).

Despite the substantial body of literature addressing IPV, several important theoretical and methodological gaps remain. In order to address these unanswered questions, the present study used a prospective, longitudinal design with a high-risk, community-based sample to examine early adolescent psychosocial markers of risk for severe IPV during the transition to adulthood. The risk factors examined in the present study were maternal

Danielle Keenan-Miller and Constance Hammen, Department of Psychology, University of California, Los Angeles; Patricia A. Brennan, Department of Psychology, Emory University.

This research was supported by National Institute of Mental Health (NIMH) Grant R01MH5223901 to C. Hammen and P. Brennan and an NIMH Ruth L. Kirschstein National Research Service Award predoctoral fellowship (Grant 5-T32-MH14584) to D. Keenan-Miller. We are grateful to the project staff in Brisbane, coordinated by Robyne Le Brocque and Sascha Hardwicke, and to Mater-University of Queensland Study of Pregnancy collaborators Jake Najman, William Bor, Michael O'Callaghan, and Gail Williams, of the University of Queensland.

Correspondence concerning this article should be addressed to Danielle Keenan-Miller, UCLA Department of Psychology, 1285 Franz Hall, Los Angeles, CA 90095. E-mail: Danikm@ucla.edu depression history, the youths' own history of depressive disorders by age 15 , and the youths' overall level of functioning in close relationships at age 15 . As described below, these psychosocial factors may contribute to a lack of opportunities to learn appropriate social skills and may be early markers of long-lasting difficulties in interpersonal relationships and of risk for IPV.

The most commonly studied psychological risk factor for IPV is antisocial personality. A significant body of research has suggested that antisocial traits may place individuals at risk for both perpetration and receipt of violence within romantic relationships (Andrews et al., 2000; Capaldi \& Clark, 1998; Capaldi \& Crosby, 1997; Ehrensaft et al., 2004; Kim \& Capaldi, 2004). Levels of antisocial behavior are often concordant between members of a couple, a pattern that is highly predictive of violence (Capaldi \& Crosby, 1997; Kim \& Capaldi, 2004). Other forms of psychopathology have not yet received the same degree of empirical investigation as potential risk factors. However, there is evidence to suggest that other disorders, including depression, may play an important role in the etiology of IPV for men who are not generally antisocial (Holtzworth-Munroe, Meehan, Herron, Rehman, \& Stuart, 2000). Holtzworth-Munroe and Stuart's (1994) batterer typology labels men who show moderate to high levels of partner violence, but low levels of extrafamilial violence, as borderline/ dysphoric and posits that these IPV perpetrators are characterized by high levels of negative affectivity and poor relationship skills. However, the studies that have examined the effect of depression within this framework have done so as a means to distinguish among a group of men who were known batterers, and have not directly tested whether depression increases one's likelihood of becoming involved in IPV. Importantly, these studies were also limited to men and did not include diagnostic measures of depression.

Other lines of research have also suggested that depression may serve an important role in predicting both perpetration and receipt of IPV during the transition to adulthood. Results of a recent meta-analysis (Stith, Smith, Penn, Ward, \& Tritt, 2003) suggest 
that concurrent depressive symptomatology is a moderate risk factor for both male violence perpetration and female victimization. One large longitudinal study found that women's, but not men's, depressive symptoms predicted male-to-female IPV over the course of 1 year (Cleveland, Herrera, \& Stuewig, 2003). Kim and Capaldi (2004) showed similar effects in a longitudinal sample of young men at risk for delinquency, whereby women's depressive symptoms predicted aggression by their partners. Some evidence suggests that involvement in physically coercive relationships persists beyond the depressive episode (Hammen \& Brennan, 2002). However, these studies have typically measured less severe forms of violence, and the role of depression in predicting severe violence remains unknown. We speculated that depression in youth is a marker of dysfunctional processes that increase the likelihood that an individual will experience relationships with maladaptive conflict-resolution strategies, including the use of severe violence.

Recent studies have drawn attention to the connection between parental depression and tendencies toward aggression and violence during childhood and young adulthood (Hay, Angold, Pawlby, Harold, \& Sharp, 2003; Kim-Cohen, Moffitt, Taylor, Pawlby, \& Caspi, 2005). However, surprisingly little attention has been given to parental depression as a potential predictor of an individual's involvement in violent intimate partnerships. Most studies examining family-of-origin characteristics as risk factors have not included measures of parental psychopathology (e.g., Andrews et al., 2000; Cleveland et al., 2003; Ehrensaft et al., 2004; Hendy et al., 2003; O’Leary, Malone, \& Tyree, 1994; Reitzel-Jaffe \& Wolfe, 2001). Though a handful of studies have considered the role of parental antisocial traits and of the parents' general emotional distress (e.g., Capaldi \& Clark, 1998; Magdol, Moffitt, Caspi, \& Silva, 1998), those studies that have examined parental psychopathology have generally not used strict diagnostic measurements.

Hammen and Brennan (2001) have suggested that children of depressed mothers may acquire dysfunctional interpersonal skills through observation of and interaction with depressed mothers, who themselves are highly likely to show maladaptive interpersonal patterns and chronic relationship difficulties. Support for this hypothesis has been obtained in studies showing that depressed children of depressed mothers have poorer social role functioning, higher levels of interpersonal difficulties, and more negative cognitions about their own social abilities than do depressed children of nondepressed mothers (Hammen \& Brennan, 2001; Hammen, Shih, Altman, \& Brennan, 2003). These social deficits, in turn, are hypothesized to contribute to the intergenerational transmission of depression, in part through the generation of stressful life events (Hammen, 1991). Given its well-established correlation with depression (Capaldi \& Crosby, 1997; Magdol et al., 1997; Stith et al., 2003), relationship violence may be one mechanism through which children of depressed mothers acquire an increased risk for developing depression. The effects of parental depression on IPV are currently in need of empirical investigation.

Both parental and offspring depression may be associated with relationship violence as a consequence of impaired social functioning. Several specific deficits within the broad domain of interpersonal skills (e.g., limited interpersonal problem-solving capabilities, inappropriate communication skills, poor impulse control) place individuals at a greater risk of both conflict and aggression within dating relationships (Lewis \& Fremouw, 2001; Schafer,
Caetano, \& Cunradi, 2004; O'Leary et al., 1994). High levels of conflict within romantic relationships, when coupled with a lack of problem-solving skills, have also been found to predict the use of physical aggression toward romantic partners by both men and women (Capaldi \& Crosby, 1997; Riggs, O’Leary, \& Breslin, 1990). Despite clear evidence that deficits in certain interpersonalskill domains place individuals at an increased risk of experiencing some forms of IPV, the effect of these deficits on severe forms of violence has not yet been examined. In addition, global measures of interpersonal functioning are in need of investigation. It is possible that global measurements of social functioning may better capture the interactions among the specific deficits known to contribute to IPV, thereby providing a more complete and accurate assessment of risk.

In addition to these important theoretical questions, several methodological limitations in previous research have constrained our knowledge of intimate partner violence. Few studies of IPV have incorporated explicit measures of severe violence (Ehrensaft et al., 2004). Common research conceptualizations of relationship violence often include fairly minor acts of physical aggression, which may or may not have clinical consequences. Information regarding the outcomes of severe violence allows for better comparison of findings obtained in community-based samples with those derived from samples obtained through women's shelters and hospitals.

Direct measurement of severe violence also provides an opportunity to address the question of whether or not gender differences exist in the use of more severe forms of violence. A significant body of evidence has accumulated to suggest that women are as likely or more likely than men to be the perpetrators of less severe violence in their romantic relationships (Archer, 2000). Despite a long-standing belief (Frieze, 2005; Richardson, 2005) that men are more likely than women to cause significant harm to their partners, recent community-based studies have shown that men and women may be equally likely to use severe violence (Ehrensaft et al., 2004; Fergusson, Horwood, \& Ridder, 2005). However, the number of studies addressing gender differences in severe intimate partner violence among community samples of young adults is small, and this area requires further study (Holtzworth-Munroe, 2005).

The present study aimed to provide further information regarding the prevalence and predictors of severe couple violence during late adolescence and young adulthood in a high-risk, communitybased sample. The participants in the present study were selected from a birth cohort study with the intention of oversampling for maternal depression, thereby selecting children who were at high risk for depression and a wide range of interpersonal impairments, possibly including intimate partner violence. Using a prospective, longitudinal design, the present study hypothesized that maternal depression history and youth depression history predict involvement in violent relationships during the transition to adulthood. Based on previous research suggesting that girls may be more affected by maternal depression than boys (Hammen \& Brennan, 2001), it was also hypothesized that the effects of maternal depression are stronger among daughters than sons. Finally, global measures of interpersonal functioning at age 15 were hypothesized to be a mediating mechanism through which personal and familial history of depression may exert an effect on relationship violence in young adulthood. 
These psychosocial risk markers were hypothesized to predict both victimization and perpetration of severe IPV. Although prior research has indicated a small number of differences in the familyof-origin and psychosocial predictors of dating violence perpetration versus victimization (Magdol et al., 1998), there are also many shared characteristics between victims and perpetrators (Lewis \& Fremouw, 2001; Magdol et al., 1998). These commonalities are at least partially attributable to the fact that violence in romantic relationships is often mutual (Kim \& Capaldi, 2004; Magdol et al., 1998). Given the associations between victimization and perpetration, and limited evidence regarding the effects of early psychosocial variables on severe violence, no a priori hypotheses regarding differential effects on victimization versus perpetration were made.

\section{Method}

\section{Participants}

From an initial sample of 816 youths studied at age 15, 706 were retained in the follow-up at age 20. Of these, 610 young adults (282 men and 328 women) completed and returned the relevant questionnaire packets on which the current results are based. The original sample of 816 families had been selected for a study of children of depressed mothers conducted in Brisbane, Queensland, Australia. The families had been selected to oversample women with self-reported depression symptoms, from a large birth cohort study of children born between 1981 and 1984 at Mater Misericordiae Mother's Hospital in Brisbane (Keeping et al., 1989). In the original birth cohort study, women had provided questionnaire information on depressive symptoms during pregnancy and at three additional time points prior to the child's 5th birthday. These scores were used to identify women with probable diagnosable depression, varying in severity and chronicity, as well as a random sample of women with no significant depression. Details of the sample and selection methods have been reported elsewhere (Hammen \& Brennan, 2002; Hammen et al., 2003). Diagnostic information is reported below.

The 610 young adults who participated in the current study did not differ from the 206 who did not participate in this phase of data collection in terms of depression history by age $15, \chi^{2}(1, N=$ $816)=0.79, p=.37$, or maternal history for depression at youth age $15, \chi^{2}(1, N=816)=1.34, p=.24$. Those who did not participate at age 20 had a lower family income at age $15, t(783)=$ -2.16, $p=.03$, and were more likely to be male, $\chi^{2}(1, N=$ $816)=18.57, p<.001$.

At the time of the age 20 interview, $43 \%$ of participants described themselves as single; the remaining $57 \%$ were dating or had been in a relationship (17\% dating casually, $14 \%$ in a serious relationship not living together, 20\% cohabiting, $2 \%$ married, $2 \%$ separated/divorced, and $2 \%$ "other"). Nearly half (45\%) worked full-time, and $18 \%$ worked part-time. Only $10 \%$ of the sample considered themselves full-time students. Most of the sample (64\%) were financially supported by parents. The majority of our sample was Caucasian (92.1\% White, 3.6\% Asian, 1\% Australian Aborigine, 0.8\% Maori).

\section{Procedures}

Interviews that occurred during the age 15 and age 20 data collections were conducted in the participants' homes by teams of two trained interviewers who were blind to the mothers' and youths' psychiatric histories. Mothers and children also completed a battery of questionnaires. All interviewers were advanced graduate students studying clinical psychology and had prior experience administering research and clinical interviews. All participants gave their written informed consent (assent) and were compensated for their time.

\section{Measures}

Maternal depression at youth age 15. Mothers were assessed for a lifetime history of major depression or dysthymia using the Structured Clinical Interview for the DSM-IV (SCID; First, Spitzer, Gibbon, \& Williams, 1995) when their children were 15 years old. Ten percent were included in a reliability study based on audiotaped interviews; weighted kappa was .84 for depression history. Mothers were classified as depressed $(n=274)$ or not depressed $(n=336)$ based on the presence/absence of a history of a major depressive episode and/or dysthymic disorder.

Youth depression at age 15. The presence and lifetime history of disorders in the child were assessed at age 15 using the Schedule for Affective Disorders and Schizophrenia for School-Age Children-Revised (Epidemiologic version-5) for the DSM-IV (K-SADS-E; Orvaschel, 1995). It was administered separately to the mother and the child, with diagnostic decisions made by the clinical rating team based on all available sources of information. Weighted kappas based on 75 interviews were .82 for current depressive disorders and .72 for past depression. At age 15, 86 youths ( 22 boys and 64 girls) in the current study had met DSM-IV criteria for major depression or dysthymia.

Youth close relationship functioning at age 15. Youth social functioning was assessed at age 15 using an adolescent version of a semistructured interview that measures chronic and episodic stress (e.g., Hammen \& Brennan, 2001). The interview measured the overall quality of three types of close relationships: close friendships, romantic relationships/dating interests, and family relationships. The overall quality of these relationships and chronic stressors in each area over the past 6 months were rated on a 5-point scale using behaviorally specific anchors, with higher scores representing more adverse conditions and poorer relationship quality. For example, the Family Relationships subscale was rated according to the following anchors: 1, "exceptional quality relationship with all family members" (including high levels of support and good conflict resolution); 3, "good quality relationship with one parent, some problems with the other parent" (including lack of communication, trust, or availability); and 5, "poor quality relationship with parents, no other family members to turn to." Intraclass correlations obtained from independent judges were .76 for the Close Friendships subscale, .55 for the Romantic Relationships subscale, and .84 for the Family Relationships subscale. All three scales were correlated with one another at or below $p=.01$. The scores across these domains were summed and $z$-scored. In addition, the interview probed for the occurrence of stressful episodic life events over the past year and obtained information about the nature of the event and the circumstances in which it occurred. Exact procedures have been detailed elsewhere (e.g., Hammen \& Brennan, 2001). The total number of stressful events related to interpersonal relationships was $z$-scored and added to the relationship quality score. Total scores on this variable were then 
Table 1

Gender and Risk Factor Profile of Young Adults Endorsing Victimization and Perpetration

\begin{tabular}{|c|c|c|c|c|c|c|}
\hline \multirow[b]{2}{*}{ Variable } & \multicolumn{3}{|c|}{ Victimization } & \multicolumn{3}{|c|}{ Perpetration } \\
\hline & $\begin{array}{l}\text { Young men } \\
(n=282)\end{array}$ & $\begin{array}{l}\text { Young women } \\
\quad(n=328)\end{array}$ & $\begin{array}{c}\text { Total } \\
(N=610)\end{array}$ & $\begin{array}{l}\text { Young men } \\
(n=282)\end{array}$ & $\begin{array}{l}\text { Young women } \\
\quad(n=328)\end{array}$ & $\begin{array}{c}\text { Total } \\
(N=610)\end{array}$ \\
\hline \multicolumn{7}{|l|}{ Endorsed item } \\
\hline Was physically injured & 20 & 55 & $75^{* * *}$ & 6 & 22 & $28^{* * *}$ \\
\hline Needed medical attention & 7 & 14 & 21 & 2 & 9 & 11 \\
\hline Sought police intervention & 6 & 25 & $31^{* * *}$ & 7 & 4 & 11 \\
\hline \multicolumn{7}{|l|}{ Any violence endorsement } \\
\hline Maternal depression present & 11 & 37 & 48 & 3 & 19 & 21 \\
\hline Youth depression present & 18 & 23 & 41 & 0 & 9 & 9 \\
\hline
\end{tabular}

${ }^{* *} p<.01$, difference between young men and women on item endorsement.

converted to standardized $z$-values. Analyses of the narratives upon which chronic and episodic stress scores were based did not indicate that these scores reflected youth IPV at age 15 .

Severe intimate partner violence at age 20. Participants completed a set of three questions regarding the levels of "severe abuse" in their intimate romantic relationships over the past 5 years. The questions asked whether they had been physically hurt, needed medical attention, or called the police due to a fight with a romantic partner. The same questions were then repeated to query about the consequences a romantic partner may have faced due to violence perpetrated by the participant. Participants responded yes or no regarding both their perpetration and receipt of severe violence. Each participant's responses to these items were then summed to create two scales: Severe Violence Perpetration and Severe Violence Victimization. Each of these scales was converted to a binary present/absent scale. ${ }^{1}$

\section{Results}

\section{Prevalence of Severe Intimate Partner Violence}

As shown in Table $1,16 \%$ of the sample $(n=101)$ reported at least one episode of severe IPV that resulted in a clinical outcome (including a need to seek medical or legal attention as a result of violence) during the past 5 years. Among participants reporting severe violence, the average number of incidents reported was 1.75 $(S D=.92)$. Women were more likely to report involvement in severe violence than men, $\chi^{2}(1, N=610)=13.30, p<.001$. Women reported victimization more often than men, $\chi^{2}(1, N=$ $610)=14.87, p<.001$, and women were somewhat more likely to report perpetration more often than men, $\chi^{2}(1, N=610)=3.50$, $p=.06$. Within the total sample of participants reporting severe intimate partner violence, 63 reported only victimization (18 men and 45 women), 13 reported only perpetration (6 men and 7 women), and 25 indicated that they had been both perpetrators and victims ( 6 men and 19 women). Correlations between the predictor and outcome variables are displayed in Table 2.

\section{Youth Severe Violence Victimization}

The contributions of gender, maternal depression history, and youth depression history (all effect coded); and the interaction of gender and maternal history of depression, to the prediction of youth victimization, were all evaluated by logistic regression.
Although our model did not initially hypothesize an interaction between gender and youth depression status, or an interaction of youth depression by maternal depression, these interactions were tested in preliminary analyses in order to fully explore gender and depression status effects. Neither interaction was significant, and these interactions were excluded from subsequent analyses. The final overall model significantly predicted victimization, $\chi^{2}(4)=$ $34.49, p<.001$. As can be seen in Table 3 , being female $(B=.41$, $S E=.13$, odds ratio $[\mathrm{OR}]=2.27, p=.002$ ) and having experienced an episode of depression prior to age $15(B=.43, S E=.15$, $\mathrm{OR}=2.36, p=.003$ ) contributed to an increased risk of being the victim of severe intimate partner violence by age 20. Maternal depression history and the interaction of maternal depression with youth gender were nonsignificant predictors.

Logistic mediation analyses were used to examine the potential mediating role of social functioning on the association between depressive history and victimization. The prerequisite conditions for mediation were met, as youth depression predicted both victimization and social functioning $(B=.38, S E=.05, p<.001)$, and social functioning was a significant predictor of victimization, controlling for depression $(B=.51, S E=.11, \mathrm{OR}=1.67, p<$ .001 ). The Sobel test was significant (Aroian test statistic $=3.13$, $p<.01$ ). Youth social functioning was a significant mediator of the relationship between youth depression and severe violence victimization.

\footnotetext{
${ }^{1}$ Use of the outcome measure based on injury, police, or medical system involvement captures the most severe "clinical" forms of violence (Ehrensaft et al., 2004), but its relationship to more common violence such as that reported on the Conflict Tactics Scales (CTS; Straus, 1979) is not known. Exclusion of such information might omit participants who experienced severe violence but did not have the specified outcomes. Given that CTS data were available for a subset of youths who were in a current relationship $(n=357)$, this possibility was addressed. Respondents completed the CTS with regard to their current relationship only, and thus it did not capture the experiences of participants whose severe violence may have occurred in previous relationships $(n=26)$ or who were not in a relationship at the time of the follow-up $(n=29)$. Despite these limitations, the same pattern of results emerged when the analyses were rerun using a binary variable representing endorsement of any of the six "severe" violence items on the CTS.
} 
Table 2

Correlation Matrix of Each Variable for Men and Women

\begin{tabular}{lccccr}
\hline \multicolumn{1}{c}{ Variable } & 1 & 2 & 3 & 4 & 5 \\
\hline 1. Social functioning & - & & & & \\
2. Youth depression & $.20^{*} / 26^{*}$ & - & & & \\
3. Maternal depression & $.18^{*} / .16^{*}$ & $.19^{*} / .09$ & - & & \\
4. Youth victimization & $.14^{*} / .25^{*}$ & $.10 / .20^{*}$ & $.00 / .13^{*}$ & - & \\
5. Youth perpetration & $.00 / .16^{*}$ & $.06 / .11^{*}$ & $-.09 / .17^{*}$ & $.31^{*} / .40^{*}$ & - \\
\hline
\end{tabular}

Note. Values for men precede the slashes; those for women follow the slashes.

${ }^{*} p \leq .05$.

\section{Youth Perpetration of Severe Violence}

The contributions of gender, maternal depression history, and youth depression history (all effect coded), along with the interaction of gender and maternal history of depression in the prediction of perpetration of severe violence, were all tested using a logistic regression analysis. Results suggested that the overall model was significant, $\chi^{2}(4)=16.81, p<.002$. As shown in Table 3, the only significant predictor of perpetration was the interaction between gender and maternal depression history ( $p=$ .005). Figure 1 shows the percentage of perpetration for both men and women as a function of maternal depression. Maternal depression history increased the likelihood that women (conditional probability $=.12,95 \%$ confidence interval $[\mathrm{CI}]=.078, .188$ ) but not men (conditional probability $=.02,95 \% \mathrm{CI}=.008, .069$ ) would perpetrate severe violence.

Logistic mediation analyses were used to examine the potential mediating role of youth social functioning on the association between maternal depression history and youth violence perpetration among the subset of female participants. All of the criteria for mediation were met, as maternal depression predicted both youth social functioning $(B=.16, S E=.04, p<.001)$ and severe violence $(B=.23, S E=.12$, OR $=1.25, p=.05)$, and youth social functioning predicted severe violence, controlling for maternal depression $(B=.58, S E=.11, \mathrm{OR}=1.78, p<.001)$. Youth social functioning was a mediator of the association be-

Table 3

Summary of Logistic Regression Equations Predicting Youth Victimization and Perpetration

\begin{tabular}{lcccc}
\hline \multicolumn{1}{c}{ Variable } & $B$ & $S E B$ & Odds ratio & $p$ \\
\hline & Victimization & & \\
Gender & 0.42 & 0.13 & 2.28 & .002 \\
Youth depression history & 0.53 & 0.14 & 2.88 & .0001 \\
Maternal depression history & 0.12 & 0.13 & 1.25 & .36 \\
Gender $\times$ Maternal Depression & 0.18 & 0.13 & & .17 \\
\hline
\end{tabular}

\begin{tabular}{lllll}
\hline \multicolumn{5}{c}{ Perpetration } \\
& & & & \\
Gender & 0.31 & 0.21 & 1.85 & .13 \\
Youth depression history & 0.27 & 0.21 & 1.52 & .20 \\
Maternal depression history & 0.06 & 0.23 & 1.58 & .74 \\
Gender $\times$ Maternal Depression & 0.76 & 0.21 & & .005 \\
\hline
\end{tabular}

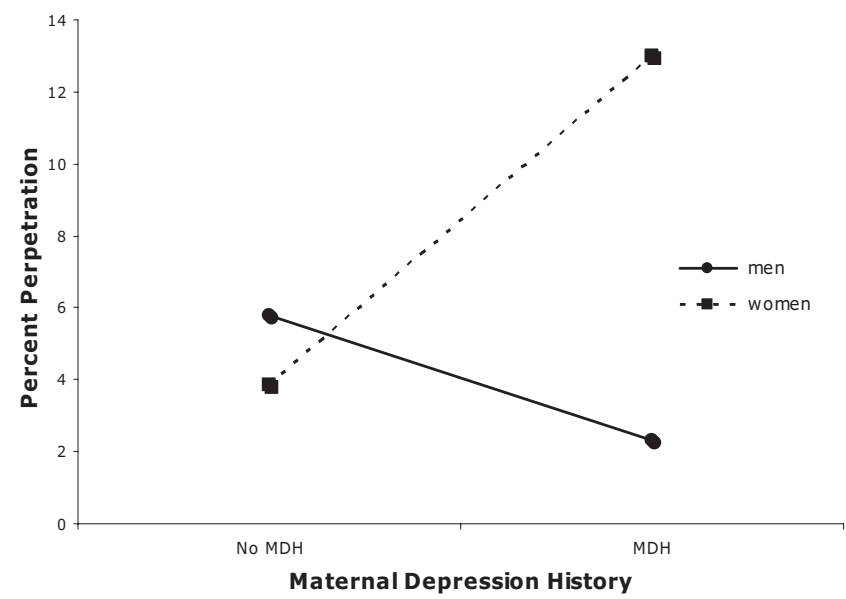

Figure 1. Percent risk of perpetrating severe violence for men and women as a function of maternal depression history. $\mathrm{MDH}=$ maternal depression history.

tween maternal depression and violence perpetration for women (Aroian test statistic $=3.17, p=.001$ ).

\section{Discussion}

The primary goals of this study were to assess severe intimate partner violence in a community sample of youths at risk for depression, and to test a model of its predictors during the transition to adulthood. The potential risk markers examined in the present study were youth history of depression diagnosis and maternal depression history by youth age 15 . A broad measure of youth social functioning in close relationships was tested as a mediator of the observed associations. In addition, the influence of gender on violence outcomes was examined.

The rate of severe violence observed in our sample over a 5-year period $(16 \%)$ was generally comparable to the rate $(9 \%)$ obtained in a similar unselected birth cohort sample over a 3-year period (Ehrensaft et al., 2004). The somewhat higher rate of violence in our sample may be attributable to both the longer time frame used in our examination of violence ( 5 years) and the fact that the present study oversampled for maternal depression, thereby including a group of youths at elevated risk for adverse outcomes. The high rate of clinical violence highlights the potential for severe consequences of intimate partner violence, even among samples not selected for their involvement in the legal or shelter systems, and underscores the need for improved prevention and intervention programs.

Gender influenced the likelihood of experiencing violence. Women were more likely than men to have experienced severe consequences as a result of victimization within their romantic relationships, including injury and the request for legal intervention. Overall, men and women reported being equally likely to have been the perpetrators of severe violence within their relationships, although women reported more often than men that they had been the perpetrators of violence that had resulted in injury. This finding is in line with that of other recent investigations using community-based samples (Ehrensaft et al., 2004), and it adds to the growing body of evidence that rates of violence perpetration 
may be equivalent between males and females even at the most severe end of the violence spectrum.

In addition to examining the prevalence of violence in our sample, the present study tested the effect of youth depression history and maternal depression history in early adolescence on involvement in severe IPV during young adulthood. Severe violence victimization was predicted by youth history of major depression or dysthymia prior to age 15 , but not by maternal depression history. Violence perpetration, however, was best predicted by the interaction between gender and maternal history of depression, such that women whose mothers had been depressed were more likely to report perpetration of severe IPV. Youth depression history did not contribute significantly to the prediction of violence perpetration. Youth social functioning at age 15 was found to be a partial mediator of both of these observed associations.

Our finding that youth depression history at age 15 was associated with severe violence victimization in young adulthood is consistent with prior research examining less severe forms of couple violence, which suggests that a history of depression predicts violent relationship outcomes (Kim \& Capaldi, 2004; Rao, Hammen, \& Daley, 1999). Previous research has shown that the relationships of individuals with a history of depression are more likely to be characterized by high levels of disagreement and low levels of satisfaction (Gotlib, Lewinsohn, \& Seeley, 1998; Zlotnick, Kohn, Keitner, \& DellaGrotta, 2000), which may contribute to an increased likelihood of severe violence within their partnerships (Capaldi \& Crosby, 1997; Riggs et al., 1990). The fact that this association was mediated in part by youth social functioning suggests that deficits in social skills and interpersonal resources may be the mechanism through which youth depression leads to victimization. Alternatively, common factors, such as impulsivity or deficits in interpersonal problem-solving skills, may directly contribute to both poor social and poor mental health functioning at age 15 , as well as to violent relationship patterns at age 20.

It is also possible that the same behavioral or personality factors that led to poor social functioning and depression among some adolescents may have also limited their choice of potential romantic partners, or contributed to the selection of partners with similar deficits. This interpretation is consistent with prior research on assortative mating patterns in affective disorders, which has shown that individuals with a history of depression often select romantic partners who show antisocial and aggressive behavioral tendencies (Capaldi \& Crosby, 1997; Cleveland et al., 2003; Kim \& Capaldi, 2004; Merikangas, 1982). In addition, the lack of opportunity for finding an alternative partner due to depression and poor interpersonal functioning may increase one's commitment to an available partner even when that partner behaves in a violent way, thereby prolonging exposure to intimate partner violence and increasing the opportunity for severe incidents of violence to occur. In support of this interpretation, youths who had experienced depression prior to age 15 were more likely to report not having had any involvement in an intimate relationship between ages 15 and 20, a finding that perhaps reflects a lower level of partner availability. ${ }^{2}$ A more thorough examination of the potential mediating role of mate selection and perceived mate availability is needed. In any case, our findings suggest that youths with relatively poor social functioning at age 15 are at risk for violent intimate relationships.

Somewhat surprisingly, youth victimization was not predicted by maternal depression history. We had expected that offspring, perhaps daughters especially, of depressed women would be more likely to be victims of IPV, such that abusive romantic relationships might be one mechanism of intergenerational transmission of depression. However, it appears that the youth's own depression is the most important factor. Given that elevated rates of depression and low self-esteem have been demonstrated among victims of relationship violence (Lewis \& Fremouw, 2001), it is likely that the relationship between IPV and depression is bidirectional. Further research should explore whether IPV victimization contributes to recurrence of depression among those with early-onset depression.

Our finding that women, but not men, whose mothers had been depressed were more likely to use severe violence against a romantic partner supports the body of research suggesting that children of depressed mothers are more prone to various forms of interpersonal aggression (Hay et al., 2003; Kim-Cohen et al., 2005). Children raised by a depressed mother are likely to grow up in stressful home environments where appropriate interpersonal skills are not consistently modeled (Hammen, Brennan, \& Shih, 2004). Given the fact that poor social functioning at age 15 partially mediated this association, it is possible that the use of severe violence in close relationships may be the result of the limited social competencies of these youths. The fact that this association holds only for daughters, and not sons, of depressed mothers may be related to the fact that modeling effects are stronger within than between genders (Bandura, 1977). Alternatively, the stronger sanctions against male-to-female violence may inhibit some men from using severe violence as a conflict resolution strategy. However, given the low base rate of endorsement of perpetration by men, these results should be interpreted with caution pending replication.

Our finding that the predictors of victimization and perpetration were different runs contrary to the results of previous research examining less severe forms of IPV. One reason that the predictors of perpetration and victimization may differ for severe violence and not for other forms of IPV is that there is less reciprocity between partners in this more severe form of violence. While many studies have found that less severe forms of intimate partner violence tend to be mutual (Kim \& Capaldi, 2004; Magdol et al., 1998), the majority (75\%) of those reporting severe violence in our sample reported only perpetration or only victimization.

This study had several methodological strengths. The use of a community-based sample limited the bias often introduced into

\footnotetext{
${ }^{2}$ Due to the fact that youths who have experienced the risk factors involved in the present analyses may have different patterns of involvement in intimate partnerships, the relationship between the hypothesized risk factors and a lack of romantic relationships over the previous 5 years was tested. A logistic regression was used to test the significance of youth and maternal depression history, youth functioning, and the interaction of these variables with gender, in predicting the absence of youth involvement in a romantic relationship between age 15 and age 20. The overall model was not significant, $\chi^{2}(6)=6.84, p=.34$. The only variable that made a significant contribution to the absence of a recent romantic relationship was youth depression history $(B=1.34, S E=.60, p=.025)$, suggesting that youths with a history of depression were less likely to have had a relationship. Because they were therefore not included in the analyses of severe violence, our power to detect effects of youth depression may be diminished.
} 
IPV research through reliance on school-based samples that may be at decreased risk of experiencing relationship violence (Capaldi $\&$ Clark, 1998). In addition, both men and women were examined as possible perpetrators and victims, whereas many studies of severe violence focus on the experiences of only one gender (e.g. Holtzworth-Munroe et al., 2000). The inclusion of severe violence measures also allows for greater understanding of the relationship between our sample and other samples of individuals who have had contact with the legal or medical system as a result of IPV. In addition, the use of prospective measures of interpersonal functioning, youth depression history, and maternal depression history by age 15 to predict IPV between 15 and 20 reduced the interference of retrospective reporting bias.

An important limitation to the present analyses is the selfreported nature of the IPV data. Although the incidents in question are likely to have been highly salient events, the length of the recall period ( 5 years) may have detracted from the accuracy of recall. Additionally, it is possible that youths may not have been aware of whether violence that they perpetrated against their partners resulted in harm and/or a need for medical attention. The fact that victimization rates were higher than perpetration rates may reflect a bias in sampling or attrition, or it may indicate that self-reports were influenced by social desirability. Our measurement of violence was also somewhat limited, in that it was meant to capture only the most extreme experiences of IPV in our sample. In making the choice to focus only on these extreme outcomes, we have certainly omitted the experiences of individuals who have had less severe but still important experiences with IPV. Severe physical violence not resulting in the specific outcomes measured showed similar patterns in a subsample of participants currently in a relationship; but mild violence may have different predictors. It is important not to assume that the risk factors found in these analyses will generalize to less severe forms of IPV. Lastly, it is important to note that the degree of injury was not directly assessed. It is possible that the psychosocial predictors studied may predispose individuals to be more likely to seek medical or legal help than are healthy individuals who have experienced similar degrees of violence. Future studies should aim to include objective measurements of injury and to verify self-reported outcomes.

Our findings may also be limited by biases in sampling and attrition. Individuals who were severely harmed as a result of IPV between follow-up periods may have been less likely to participate in the age-20 phase of data collection. For example, some participants may have moved or changed contact information as a way of escaping violent romantic partners. There was one study member who was murdered by her boyfriend between phases of data collection and whose experience of violence could not be captured in our present analyses. The severity of that experience is thereby underrepresented in our data, although it continues to serve as a stark reminder of the severe risk that many of these young adults face as a result of the violence within their intimate partnerships. In addition, our sample had considerable cultural and ethnic homogeneity. These predictors were tested only on Australian 20year-olds, the vast majority of whom were Caucasian. Australia is similar to the United States and United Kingdom in terms of the sanctions against violence and the availability of community resources dedicated to domestic violence, and there is no evidence to suggest that these findings should not generalize to other Westernized samples. However, previous research has highlighted the potential for significant differences among ethnic groups in the predictive validity of risk factors for relationship violence (Schafer et al., 2004). Further research with more diverse samples is needed.

The present study makes an important contribution by using a community-based sample and prospectively measured psychosocial risk factors to predict the development of severe violence among couples. The present findings indicate that measures of psychosocial functioning in early adolescence may be used to identify youths at risk for becoming involved in severely violent romantic relationships in young adulthood. Specifically, depression during adolescence may serve as an important risk factor for future victimization, and, among women, maternal depression may be an important risk factor for violence perpetration. These associations were partially mediated by youth social functioning, a risk factor which may be amenable to change through proper intervention. Intervention programs targeting adolescents with these risk factors are urgently needed. The economic cost of IPV in the United States is estimated to reach over $\$ 8$ billion (Max et al., 2004), suggesting that the development of targeted intervention programs may be economically viable. Social-skills training and depression treatment should be investigated as methods of attenuating the risk of IPV among these at-risk youths.

\section{References}

Andrews, J. A., Foster, S. L., Capaldi, D., \& Hops, H. (2000). Adolescent and family predictors of physical aggression, communication, and satisfaction in young adult couples: A prospective analysis. Journal of Consulting and Clinical Psychology, 68, 195-208.

Archer, J. (2000). Sex differences in aggression between heterosexual partners: A meta-analytic review. Psychological Bulletin, 126, 651-680.

Bandura, A. (1977). Social learning theory. Englewood Cliffs, NJ: Prentice Hall.

Capaldi, D. M., \& Clark, S. (1998). Prospective family predictors of aggression toward female partners for at-risk young men. Developmental Psychology, 34, 1175-1188.

Capaldi, D. M., \& Crosby, L. (1997). Observed and reported psychological and physical aggression in young, at-risk couples. Social Development, 6, 184-206

Cleveland, H. H., Herrera, V. M., \& Stuewig, J. (2003). Abusive males and abused females in adolescent relationships: Risk factor similarity and dissimilarity and the role of relationship seriousness. Journal of Family Violence, 18, 325-339.

Ehrensaft, M. K., Moffitt, T. E., \& Caspi, A. (2004). Clinically abusive relationships in an unselected birth cohort: Men's and women's participation and developmental antecedents. Journal of Abnormal Psychology, 113, 258-270.

Fergusson, D. M., Horwood, L. J., \& Ridder, E. M. (2005). Partner violence and mental health outcomes in a New Zealand birth cohort. Journal of Marriage and the Family, 67, 1103-1119.

First, M. B., Spitzer, R. L., Gibbon, M., \& Williams, J. B. W. (1995). Structured Clinical Interview for the DSM-IV Axis I disorders. Washington, DC: American Psychiatric Press.

Frieze, I. H. (2005). Female violence against intimate partners: An introduction. Psychology of Women Quarterly, 29, 229-237.

Gerber, M. R., Ganz, M. L., Lichter, E., Williams, C. M., \& McCloskey, L. A. (2005). Adverse health behaviors and the detection of partner violence by clinicians. Archives of Internal Medicine, 165, 1016-1021.

Gotlib, I. H., Lewinsohn, P. M., \& Seeley, J. R. (1998). Consequences of depression during adolescence: Marital status and marital functioning in early adulthood. Journal of Abnormal Psychology, 107, 686-690. 
Hammen, C. (1991). Generation of stress in the course of unipolar depression. Journal of Abnormal Psychology, 100, 555-561.

Hammen, C., \& Brennan, P. A. (2001). Depressed adolescents of depressed and nondepressed mothers: Tests of an interpersonal impairment hypothesis. Journal of Consulting and Clinical Psychology, 69, 284-294.

Hammen, C., \& Brennan, P. A. (2002). Interpersonal dysfunction in depressed women: Impairments independent of depressive symptoms. Journal of Affective Disorders, 72, 145-156.

Hammen, C., Brennan, P. A., \& Shih, J. H. (2004). Family discord and stress predictors of depression and other disorders in adolescent children of depressed and nondepressed women. Journal of the American Academy of Child and Adolescent Psychiatry, 43, 994-1002.

Hammen, C., Shih, J., Altman, T., \& Brennan, P. A. (2003). Interpersonal impairment and the prediction of depressive symptoms in adolescent children of depressed and nondepressed mothers. Journal of the American Academy of Child and Adolescent Psychiatry, 42, 571-577.

Hay, D. F., Angold, A., Pawlby, S., Harold, G. T., \& Sharp, D. (2003). Pathways to violence in the children of mothers who were depressed postpartum. Developmental Psychology, 39, 1083-1094.

Hendy, H. M., Weiner, K., Bakerofskie, J., Eggen, D., Gustitus, C., \& McLeod, K. C. (2003). Comparison of six models for violent romantic relationships in college men and women. Journal of Interpersonal Violence, 18, 645-665.

Holtzworth-Munroe, A. (2005). Male versus female intimate partner violence: Putting controversial findings into context. Journal of Marriage and the Family, 67, 1120-1125.

Holtzworth-Munroe, A., Meehan, J. C., Herron, K., Rehman, U., \& Stuart, G. L. (2000). Testing the Holtzworth-Munroe and Stuart (1994) batterer typology. Journal of Consulting and Clinical Psychology, 68, 10001019.

Holtzworth-Munroe, A., \& Stuart, G. L. (1994). Typologies of male batterers: Three subtypes and the differences among them. Psychological Bulletin, 116, 476-497.

Keeping, J. D., Najman, J. M., Morrison, J., Western, J. S., Andersen, M. J., \& Williams, G. M. (1989). A prospective longitudinal study of social, psychological, and obstetrical factors in pregnancy: Response rates and demographic characteristics of the 8,556 respondents. British Journal of Obstetrics and Gynecology, 96, 289-297.

Kim, H. K., \& Capaldi, D. M. (2004). The association of antisocial behavior and depressive symptoms between partners and risk for aggression in romantic relationships. Journal of Family Psychology, 18, 82-96.

Kim-Cohen, J., Moffitt, T. E., Taylor, A., Pawlby, S. J., \& Caspi, A. (2005). Maternal depression and children's antisocial behavior. Archives of General Psychiatry, 62, 173-181.

Lewis, S. F., \& Fremouw, W. (2001). Dating Violence: A critical review of the literature. Clinical Psychology Review, 21, 105-127.
Magdol, L., Moffitt, T. E., Caspi, A., Newman, D. L., Fagan, J., \& Silva, P. A. (1997). Gender differences in partner violence in a birth cohort of 21-year-olds: Bridging the gap between clinical and epidemiological approaches. Journal of Consulting and Clinical Psychology, 65, 68-78.

Magdol, L., Moffitt, T. E., Caspi, A., \& Silva, P. A. (1998). Developmental antecedents of partner abuse: A prospective-longitudinal study. Journal of Abnormal Psychology, 107, 375-389.

Max, W., Rice, D. P., Finkelstein, E., Bardwell, R. A., \& Leadbetter, S. (2004). The economic toll of intimate partner violence against women in the United States. Violence and Victims, 19(3), 259-272.

Merikangas, K. R. (1982). Assortative mating and affective disorders. Journal of Affective Disorders, 1, 247-253.

O’Leary, K. D., Malone, J., \& Tyree, A. (1994). Physical aggression in early marriage: Prerelationship and relationship effects. Journal of Consulting and Clinical Psychology, 62, 594-602.

Orvaschel, H. (1995). Schedule for Affective Disorders and Schizophrenia for School-Age Children-Epidemiologic Version-5. Ft. Lauderdale, FL: Nova Southeastern University, Center for Psychological Studies.

Rao, U., Hammen, C., \& Daley, S. E. (1999). Continuity of depression during the transition to adulthood: A 5-year longitudinal study of young women. Journal of the American Academy of Child and Adolescent Psychiatry, 38, 908-915.

Reitzel-Jaffe, D., \& Wolfe, D. A. (2001). Predictors of relationship abuse among young men. Journal of Interpersonal Violence, 16, 99-115.

Richardson, D. S. (2005). The myth of female passivity: Thirty years of revelations about female coercion. Psychology of Women Quarterly, 29, $238-247$.

Riggs, D., O'Leary, K., \& Breslin, F. (1990). Multiple predictors of physical aggression in dating couples. Journal of Interpersonal Violence, 5, 61-73.

Schafer, J., Caetano, R., Cunradi, C. B. (2004). A path model of risk factors for intimate partner violence among couples in the United States. Journal of Interpersonal Violence, 19, 127-142.

Stith, S. M., Smith, D. B., Penn, C. E., Ward, D. B., \& Tritt, D. (2003). Intimate partner physical abuse perpetration and victimization risk factors: A meta-analytic review. Aggression and Violent Behavior, 10, 65-98.

Straus, M. A. (1979). Measuring intrafamily conflict and violence. Journal of Marriage and the Family, 41, 75-88.

Zlotnick, C., Kohn, R., Keitner, G., \& DellaGrotta, S. (2000). The relationship between quality of interpersonal relationships and major depressive disorder: Findings from the National Comorbidity Survey. Journal of Affective Disorders, 59, 205-215.

Received June 21, 2006

Revision received February 1, 2007

Accepted February 2, 2007 